Article

\title{
The influence of reminder book to adherence of heart failure patients in Malang city
}

\author{
Alfrina Hany, Rizqa Fadlila, Endah Panca Lydia \\ School of Nursing, Faculty of Medicine, Universitas Brawijaya, Malang, Indonesia
}

\begin{abstract}
Background: Non-adherence to the recommended therapy causes patients with heart failure to experience recurrence of the disease. Reminder book on therapy adherence is very useful, because it assists in monitoring adherence to therapy carried out by patients while at home. Therefore, this study aims to determine the effect of the existence of a reminder book on adherence to therapy among patients with heart failure in a private hospital in Malang.

Design and Methods: A pre-experiment design with one-group pre and posttest was used. The respondents were 18 patients that received counseling on the management of heart failure therapy while at home and were given a reminder book. Furthermore, the modified MMAS- 8 scale was the study instrument used to measure adherence.

Result: The results showed that most respondents were above the age of 65 with a treatment duration of 1 to 5 years. It was discovered that most of the respondents had never received information about heart failure therapy. Data analysis which was carried out using the Wilcoxon test with a p-value of 0.001 , showed that there was a significant difference between respondents' compliance before and after being given a reminder book.

Conclusions: From this study, it was concluded that providing a reminder book has an effect on therapeutic adherence in patients with heart failure. Researchers recommend that hospitals should make use of this reminder as a tool to control or supervise outpatient therapy.
\end{abstract}

\section{Introduction}

Heart failure is the inability of the heart to pump adequate amount of blood to meet the tissue's demand for oxygen and nutrients. The term heart failure denotes a myocardial disease in which there is a problem with the heart's contraction (systolic dysfunction) or filling (diastolic dysfunction), which may be causing pulmonary congestion or systemic congestion. Currently, heart failure is recognized as a clinical syndrome characterized by signs and symptoms of fluid overload and inadequate tissue perfusion. ${ }^{1-3}$

Based on the American Heart Association (AHA), the prevalence of heart failure in 2017 increased from 5.7 million (in 20092012) to 6.5 million (in 2011-2014) at the age of 20 and above.
Basic Health Research (Riskesdas) in $2013^{4}$ showed that the most encountered heart disease in adults is coronary heart disease and heart failure. East Java is the province with the second largest prevalence of heart failure of $0.19 \%$, after Yogyakarta, Central Java, of $0.25 \%$. Based on age group above 15 years, the highest incidence rate of heart failure in East Java province is in Malang Regency at $0.5 \%$, while in Malang City the incidence of heart failure is $0.1 \%$. According to doctor's diagnosis, the prevalence of heart failure increases with age, the highest is at the age of 65-74 years $(0.5 \%)$ and is more common in women $(0.2 \%)$ compared to men $(0.1 \%)$.

Patients with heart failure often return to the clinic or hospital due to recurrent episodes. Based on the study carried out in America, ${ }^{5}$ it was discovered that $27 \%$ and $30 \%$ of patients with heart failure experienced rehospitalization within 30 days and 6090 days respectively and $337 \%$ of this rehospitalization was due to recurrence episodes. The precipitation factors from the rehospitalization consisted of cardiac (unmodifiable) and patient-related factors (modifiable). The cardiac factors include myocardial ischemia, atrial fibrillation and uncontrolled hypertension. Meanwhile, patient-related factors include non-adherence to medical therapy and diet, drug and alcohol abuse, inadequate access to follow-up care and poor transition of care. ${ }^{6}$ Study described other factors relating to patients, namely excessive physical activity and not being able to recognize symptoms of recurrence. ${ }^{1}$ Data from study ${ }^{5}$ explained that the high problem of rehospitalization was due to patient non-compliance with therapy. 7,8

This is in accordance with the guidelines for the management of heart failure compiled by the Indonesian Association of Cardiovascular Specialists (PERKI) in 2015, which states that only $20-60 \%$ of patients adhere to pharmacological and non-pharmacological therapies. It is stated that non-adherence to therapy in patients with heart failure increase morbidity, mortality and reduce the patient's quality of life. ${ }^{9,10}$ Therefore, it is necessary to take action to improve adherence to therapy in patients with heart failure. ${ }^{11}$ One of the actions that may be taken is self-management intervention. This is in accordance with the study ${ }^{12}$ carried out on the effect of self-management in improving health outcomes among elderly people with heart failure. Self-management behavior and symptoms related to heart failure in the control group were also lower compared to the intervention group. Good self-care is correlated to better quality of life. ${ }^{13}$ It is hoped that the improvement in therapy adherence reduces the rehospitalization rate dan increased quality of life. ${ }^{13-15}$ Based on study carried out on the

The number of patients diagnosed with heart failure is increasing yearly, including rehospitalization rates. Adherence to therapy among patients with heart failure is important in preventing recurrence. One of the ways in improving adherence is the use of self-management techniques, such as independent monitor therapy. An example of this therapy is the use of a reminder book which helps to improve adherence and self-efficacy in patients with heart failure. 
effect of self-management interventions on heart failure patients, the results showed that respondents in the intervention group experienced fewer hospitalizations and the quality of life of respondents in this group also increased for 12 months. ${ }^{16}$ One of the selfmanagement techniques that should be carried out by patients is to independently monitor their therapy, for example by providing a reminder book. A study argued that a treatment reminder system is defined as a medical service that helps patients remember the schedule for taking medication and its dosage. ${ }^{17}$ Furthermore, from study carried out on reducing recurrence and improving the quality of care using a checklist in patients with heart failure, it was discovered that the use of a discharge checklist led to higher proportion of patients using recommended drugs, higher proportion of drug titration and a decrease in recurrence in 30 days and 6 months. ${ }^{18}$ The results of the two studies above indicate that book reminders improve patient adherence, reduce readmission and improve the quality of care.

A book of reminder is a message that helps people remember things which are usually found in important notes. Medication reminder system is a medical service that helps patients keep track of their medication schedule, including the dosage of the drug. This system is usually provided by medical personnel using a media checklist for a medication schedule. ${ }^{19}$ In addition, the reminder book is used to monitor dietary adherence, fluid management and the activity of patients with heart failure.

In Malang city hospital, the use of this reminder book has not been implemented. The data used by the researchers were obtained from one of the private hospitals in Malang city, with the number of patients with heart failure cases in June-August 2018 been 152 inpatients. There were 12 patients that underwent rehospitalization or $7.8 \%$ of the total hospitalized patients. Outpatients from June to August 2018 were 1871 patients, but those that returned to control were only 155 patients or $8.2 \%$ of the total outpatients. Furthermore, based on the results of a preliminary study carried out on the 17 patients that encountered heart failure, $35 \%$ underwent rehospitalization and $52 \%$ of patients did not undergo rehospitalization. The results of the interview showed that $100 \%$ of patients that experienced rehospitalization were not adherent to drug therapy and $33 \%$ did not adhere to diet and activity therapy. Meanwhile, over $83 \%$ of patients that experienced rehospitalization admitted that they were not knowledgeable about heart failure and its therapy, including how to monitor its therapy. Therefore, this study aims to determine the effect of the existence of a reminder book on adherence to therapy among patients with heart failure in a private hospital in Malang.

\section{Design and Methods}

A pre-experiment design with one-group pre and posttest was used. The respondents used were 18 patients with heart failure undergoing rehospitalization at one of the private hospitals in Malang city, East Java Province. The sampling technique used in this study was nonprobability which includes total sampling. Data were collected from November to December 2018, the inclusion criteria were all patients with heart failure that were hospitalized during data collection in June to August 2018 and signed the informed consent. Data were analyzed with Wilcoxon test using SPSS 16 for Windows.

\section{Results and Discussions}

In Table 1, the characteristics of respondents based on gender showed the same number of women and men, which included 9 people each $(50 \%)$, while based on age indicated that most of the respondents were older people, as much as $9(50 \%)$. Based on comorbidities, it was discovered that most of the respondents which included 11 people $(61.1 \%)$ had comorbidities. Furthermore, it was discovered that the length of treatment undertaken by the dominant respondents which included 11 people $(61.1 \%)$ was between $1-5$ years. Based on information about heart failure therapy, most respondents which included 11 people $(61.1 \%)$ did not receive information. Prior knowledge will help heart failure patients to know more about the therapy. Socialization about therapy will increase the adherence of patients to their. $^{20,21}$

It was discovered that the measurement of adherence to pre-test therapy (Table 2) was obtained from 18 respondents who adhere to heart failure therapy. A total of 1 respondent $(5.6 \%)$ adhered to heart failure therapy, 3 respondents $(16.7 \%)$ were less obedient to the therapy, while 14 respondents $(77.8 \%$ ) failed to adhere to the therapy. It showed that the measurement of adherence to post-test therapy was obtained from 18 respondents. A total of 6 respondents (33.3\%) were adherent to heart failure therapy, 9 respondents $(50 \%)$ were less obedient to the therapy, while 3 respondents $(16.7 \%)$ failed to adhere to the therapy.

Furthermore, from Table 3, it was discovered that the comparison of adherence to pre- and post-test heart failure therapy produced a p-value of 0.001 which was less than 0.05 therefore, $\mathrm{H} 0$ was rejected.

Table 1. Characteristics of respondents.

\begin{tabular}{lcc} 
& n & F\% \\
Gender & & \\
$\quad$ Female & 9 & $50 \%$ \\
$\quad$ Male & 9 & $50 \%$ \\
Age & & \\
$\quad$ Teenage (12-25 years) & 1 & $5.6 \%$ \\
$\quad$ Early elder (46-55 years) & 4 & $22.2 \%$ \\
$\quad$ Late elder (56-65 years) & 4 & $22.2 \%$ \\
$\quad$ Very late elder (>65 years) & 9 & $50 \%$ \\
\hline Comorbidities & & \\
$\quad$ Yes & 11 & $61.1 \%$ \\
$\quad$ No & 7 & $38.9 \%$ \\
Length of treatment & & \\
$\quad<1$ year & 2 & $11.1 \%$ \\
$\quad 1-5$ years & 11 & $61.1 \%$ \\
$\quad>5$ years & 5 & $27.8 \%$ \\
\hline Education of heart failure therapy & & \\
$\quad$ Yes & 7 & $38.9 \%$ \\
$\quad$ No & 11 & $61.1 \%$ \\
\hline
\end{tabular}

Table 2. Adherence to therapy (pre-test - post-test).

Adherence pre-test Obedient $1(5.6 \%)$ $3(16.7 \%)$

Disobedient

Adherence post-test

Obedient

$6(33.3 \%)$

Less obedient

Disobedient

$9(50 \%)$ $3(16.7 \%)$

Table 3. Comparison of pre- and post-test.

\begin{tabular}{lcccc} 
& \multicolumn{3}{c}{ Adherence to therapy } & p \\
& Obedient & Less obedient & Disobedient & \\
Pre-test & $1(5.6 \%)$ & $3(16.7 \%)$ & $14(77.8 \%)$ & 0.001 \\
Post-test & $6(33.3 \%)$ & $9(50 \%)$ & $3(16.7 \%)$ & 0.001 \\
\hline
\end{tabular}


This may be interpreted that there is a difference in the level of adherence to heart failure therapy of pre- and post-test. The results obtained from the measurement of pre-test and post-test adherence, showed that the 1 person $(5.6 \%)$ that adhered to the therapy during the pre-test increased to 6 people $(33.3 \%)$ during the post-test, 3 people $(16.7 \%)$ increased to 9 people $(50 \%)$ during the post-test and the 14 respondents $(77.8 \%)$ that failed to adhere to therapy during the pre-test decreased to $3(16,7 \%)$ during the post test. From the results of pre-test therapy adherence, it was discovered that the 1 respondent $(5.6 \%)$ who adhered to therapy increased to $6(33.3 \%)$ during post-test therapy. The respondents that were less adherent to therapy also experienced an increase from $3(16.7 \%)$ at the pre-test to $9(50 \%)$ at the post-test, while respondents that failed to comply experienced a significant decrease from 14 $(77.8 \%)$ to $3(16.7 \%)$ during the post-test.

This was because at the time of the pre-test, the respondents had not received a reminder book and $61.1 \%$ of the respondents had not received information related to heart failure therapy. These data indicate that the respondents had low knowledge regarding heart failure therapy, implying the respondents low adherence to the therapy given. ${ }^{22}$ The results of measuring adherence to therapy differed after the respondents were educated on heart failure therapy and were given a reminder book. Meanwhile, the results of the measurement of adherence increased compared to what was gotten during the post-test.

The increase in adherence to therapy was in accordance with the function of the reminder book itself. A study ${ }^{19}$ argued that a treatment reminder system is defined as a medical service that helps patients remember the schedule for taking medication and its dosage. The use of reminder checklists was also developed ${ }^{18}$ in their study of decreased readmission and improved quality of care in patients with heart failure. They recommended that the best way to use checklists to improve the quality of care was by providing oral education to the patient's home and carrying out written documentation using a checklist. ${ }^{23}$ This study got positive results, which included a decrease in the spread of the transmission in patients with heart failure that were the respondents.

In this study, researchers used a reminder to improve drug therapy adherence to hypertensive patients. Furthermore, positive results were obtained positive, which includes that there was a difference in the level of adherence in the intervention group that received a checklist reminder compared to the control group who did not get a checklist reminder. Another benefit of this reminder system was also explained ${ }^{19}$ in this study carried out on an SMS Gateway based patient treatment reminder application. According to the study, the implementation of this system is quite easy and cheap. The current system also helps the hospital authorities improve the performance of the hospital in controlling and supervising patients in outpatient conditions and helping the treatment process of patients who require routine treatment. ${ }^{24,25}$

The results of the studies provided information on the benefits that may be obtained from using a reminder system which includes i) improve adherence to therapy; ii) improve the quality of care; iii) decrease readmission; iv) help hospitals improve performance in controlling and supervising patients in outpatient conditions; v) assisting the treatment process of patients who need routine medication. The researcher chose to use a reminder system using a reminder book, taking into account the age of the respondents, most of whom were late elderly. Furthermore, there was a concern that it would be difficult to use the reminder system based on respondent's application. Another consideration was that the researcher hoped the reminder book would be mobile, to enable the respondents carry it anywhere, when traveling or on a trip.

\section{Conclusions}

From this study, the results of the measurement of adherence at pre- and post-test showed differences in respondent's adherence to therapy. Furthermore, in the post-test measurement, it was discovered that the majority of adherence was to therapy.

Correspondence: Alfrina Hany, School of Nursing, Faculty of Medicine, Universitas Brawijaya, Jl. Puncak Dieng, Kunci, Kalisongo, Kec. Dau, Malang, East Java 65151, Indonesia.

Tel. +62.341569117- Fax: +62.341564755. E-mail: hanie.fk@ub.ac.id

Key words: Reminder book; adherence to therapy; heart failure.

Contributions: All the authors made a substantive intellectual contribution, have read and approved the final version of the manuscript and agreed to be accountable for all aspects of the work.

Conflict of interest: The authors declare that they have no competing interests, and all authors confirm accuracy.

\section{Funding: none}

Acknowledgments: The author expresses gratitude to School of Nursing, Faculty of Medicine, Universitas Brawijaya Malang, Indonesia for their kind support and encouragements during this study.

Ethical Approval: This study was carried out after obtaining ethical permission from the Health Research Ethics Commission of the Faculty of Medicine, Universitas Brawijaya No. 336 / EC / KEPK-S1PSIK / 12/2018.

Conference presentation: Part of this study was presented at the $1^{\text {st }}$ International Nursing and Health Sciences Symposium, November $13^{\text {th }}$ to $15^{\text {th }} 2020$, Brawijaya University, Malang, Indonesia.

Received for publication: 20 January 2021.

Accepted for publication: 24 March 2021.

oCopyright: the Author(s), 2021

Licensee PAGEPress, Italy

Journal of Public Health Research 2021;10:2158

doi:10.4081/jphr.2021.2158

This work is licensed under a Creative Commons Attribution NonCommercial 4.0 License (CC BY-NC 4.0).

\section{References}

1. Smeltzer S, Bare B, Hinkle J, et al. Brunner \& Suddart's Textbook of Medical-Surgical Nursing. 12th ed. Wolters Kluwer Health. China; 2010.

2. Hobbs FDR, Doust J, Mant J, et al. Heart failure: Diagnosis of heart failure in primary care. Heart 2010;96:1773-7.

3. Shah BR, DerSarkissian M, Tsintzos SI, et al. Adherence to heart failure management medications following cardiac resynchronization therapy. Curr Med Res Opin 2020;36:199207.

4. Ministry of Health Republic of Indonesia. Basic Health Research 2018. Jakarta: Ministry of Health Republic of Indonesia; 2013.

5. Gheorghiade M, Vaduganathan M, Fonarow GC, et al. Rehospitalization for heart failure: Problems and perspectives. J Am Coll Cardiol 2013;61:391-403.

6. Benjamin EJ, Blaha MJ, Chiuve SE, et al. Heart disease and 
stroke statistics-2017 update: A report from the American Heart Association. Circulation 2017;135:e146-603.

7. Shah D, Simms K, Barksdale D, Wu J-R. Improving medication adherence of patients with chronic heart failure: challenges and solutions. Res Reports Clin Cardiol 2015;6:87-95.

8. Hany A, Cahyanti T. Effect MOTENSI apps on adherence behavior taking antihipertensive drugs in patients with hypertension in malang city health care. In Proceedings of Int Nurs Heal Sci Symp 2020. Malang: Jurusan Keperawatan FK UB; 2020.

9. Ruppar TM, Delgado JM, Temple J. Medication adherence interventions for heart failure patients: A meta-analysis. Eur J Cardiovasc Nurs 2015;14:395-404.

10. Ruppar TM, Cooper PS, Mehr DR, et al. Medication adherence interventions improve heart failure mortality and readmission rates: Systematic review and meta-analysis of controlled trials. J Am Heart Assoc 2016;5:1-18.

11. Unverzagt S, Meyer G, Mittmann S, et al. [Verbesserung der Adhärenz bei Herzinsuffizienz: Systematisches Review und Metaanalyse zu Interventionen bei medikamentöser Therapie und Lebensstilmodifikationen].[Article in German] Dtsch Arztebl Int 2016;113:423-30.

12. Aghamohammadi T, Khaleghipour M, Shahboulaghi F, et al. Effect of self-management program on health status of elderly patients with heart failure: a single-blind, randomized clinical trial. J Acute Dis 2019;8:179.

13. Koirala B, Dennison Himmelfarb CR, Budhathoki C, Davidson PM. Heart failure self-care, factors influencing selfcare and the relationship with health-related quality of life: A cross-sectional observational study. Heliyon 2020;6:e03412.

14. Hany A. Quality of life and mental emotional health of elderly people. Jurnal Ilmu Keperawatan 2018;6:22-8.

15. Putri HR, Hany A, Kartika AW. The effectivity of health education follow up to family support in self care. Proceedings 5 th
Int Conf Nurs 2019. Malang: Jurusan Keperawatan FK UB; 2019.

16. Jonkman NH, Westland H, Groenwold RHH, et al. Do selfmanagement interventions work in patients with heart failure. J Card Fail 2016;22:861-71.

17. Fenerty SD, West C, Davis SA, et al. The effect of reminder systems on patients' adherence to treatment. Patient Prefer Adherence 2012;6:127-35.

18. Basoor A, Doshi NC, Cotant JF, et al. Decreased readmissions and improved quality of care with the use of an inexpensive checklist in heart failure. Congest Hear Fail 2013;19:200-6.

19. Willeyam W, Sevani GN. [Aplikasi Reminder Pengobatan Pasien Berbasis Sms Gateway].[Article in Indonesian]. Inkom 2013;7:11-20.

20. Lestari CA, Hany A. The effect of "MOTENSI" application on low salt diet adherence in hypertensive patient at the Malang City public health center. Malang: Jurusan Keperawatan FK UB; 2020.

21. Seid MA, Abdela OA, Zeleke EG. Adherence to self-care recommendations and associated factors among adult heart failure patients. From the patients' point of view. PLoS One 2019;14:1-13.

22. Lennie TA, Chung ML, Moser DK. What should we tell patients with heart failure about sodium restriction and how should we counsel them? Curr Heart Fail Rep 2013;10:219-26.

23. Giudicessi JR, Ackerman MJ. Determinants of incomplete penetrance and variable expressivity in heritable cardiac arrhythmia syndromes. Transl Res 2013;161:1-4.

24. Saghaeiannejad-Isfahani S, Ehteshami A, Savari E, et al. Developing the medication reminder mobile application "seeb." Acta Inform Medica 2017;25:108-11.

25. Imaligy EU. [Gagal jantung pada geriatri].[Article in Indonesian]. Cermin Dunia Kedokteran 2014;41:19-24. 